\title{
Desigualdade ambiental no município de São Paulo: análise da exposição diferenciada de grupos sociais a situações de risco ambiental através do uso de metodologias de geoprocessamento
}

\author{
Humberto Prates da Fonseca Alves*
}

\begin{abstract}
Este trabalho procura operacionalizar empiricamente o conceito de desigualdade ambiental, para identificar e caracterizar situações de desigualdade ambiental no município de São Paulo, através da utilização de metodologias de geoprocessamento. O objetivo é verificar e medir a existência (ou não) de associação entre piores condições socioeconômicas e maior exposição ao risco ambiental. Assim, são analisados os diferentes grupos sociais expostos a situações de risco ambiental, no município de São Paulo. A hipótese é de que os riscos ambientais são distribuídos de maneira desigual entre os diferentes grupos sociais, assim como a renda e o acesso a serviços públicos. Para testar essa hipótese, realizou-se uma análise comparativa da dinâmica demográfica e socioeconômica entre as populações residentes em áreas de risco ambiental e aquelas não residentes nestes tipos de área, com base em uma tipologia da distribuição espacial dos habitantes do município de São Paulo em três grupos sociais (pobres, classe média e classe alta). Os resultados mostram que, em todos os grupos sociais, as populações residentes em áreas de risco ambiental apresentam condições socioeconômicas significativamente piores do que as não residentes nessas áreas. Os resultados também revelam um aumento da desigualdade ambiental, no período recente.
\end{abstract}

Palavras-chave: Desigualdade ambiental. Risco ambiental. Grupos sociais. Município de São Paulo. Populações em situação de risco. Geoprocessamento.

Introdução

Este trabalho procura operacionalizar, do ponto de vista empírico, o conceito de desigualdade ambiental, através da utilização de indicadores e metodologias de geoprocessamento, para identificação e caracterização de situações de desigualdade ambiental no município de São Paulo. Para fins metodológicos e analíticos, define-se desigualdade ambiental como a exposição diferenciada de grupos sociais a situações de risco ambiental.
$\mathrm{O}$ argumento da desigualdade ambiental emerge da hipótese de que determinados grupos sociais, como algumas minorias e grupos de baixa renda, estariam mais expostos a certos tipos de risco ambiental, tais como enchentes, deslizamentos, etc. As áreas de risco ambiental (próximas de lixões, sujeitas a inundações e desmoronamentos), muitas vezes, são as únicas acessíveis às populações de mais baixa renda, que acabam construindo nesses locais domicílios em condições precárias, além de enfrentarem outros problemas am-

\footnotetext{
* Economista, doutor em Ciências Sociais (Unicamp), pós-doutorando e pesquisador do Centro de Estudos da Metrópole (CEM-Cebrap) e da Divisão de Processamento de Imagens (DPI-Inpe).
} 
bientais, sanitários e de saúde (TORRES, 1997; 2000).

Nesse sentido, procurou-se testar empiricamente a hipótese de que existe uma associação positiva entre piores condições socioeconômicas e maior exposição a risco ambiental, configurando-se situações de desigualdade ambiental. Ou seja, a hipótese é de que os riscos ambientais são distribuídos de maneira desigual entre os diferentes grupos sociais, assim como a renda e o acesso a serviços públicos. Deste modo, a desigualdade social estaria na origem da desigualdade ambiental, uma vez que indivíduos e grupos sociais possuem acesso diferenciado a bens e amenidades ambientais (ou à qualidade ambiental).

O objetivo geral deste trabalho é operacionalizar empiricamente o conceito de desigualdade ambiental, para identificar e caracterizar situações de desigualdade ambiental na metrópole paulistana na atualidade. Para tanto, utilizaram-se indicadores e metodologias de geoprocessamento, visando verificar e medir a existência (ou não) de associação entre piores condições socioeconômicas e maior exposição ao risco ambiental. Além disso, procurou-se verificar se a desigualdade ambiental está ou não aumentando no município de São Paulo, no período recente.

Para alcançar este objetivo, analisou-se o grau de exposição dos diferentes grupos sociais a situações de risco ambiental, no município de São Paulo. Para isso, realizouse uma análise comparativa da dinâmica demográfica e socioeconômica entre as populações residentes em áreas de risco ambiental e aquelas não residentes nestes tipos de área, com base em uma tipologia da distribuição espacial da população de São Paulo em três grandes grupos sociais (pobres, classe média e classe alta), proposta por Marques (2005).

Assim, através das análises realizadas, são propostas algumas metodologias de geoprocessamento para a operacionalização empírica do conceito de desigualdade ambiental. Acreditamos que o desenvolvimento de análises empíricas, em particular as quantitativas e espaciais, deve ser parte importante da agenda para o avanço da pesquisa em torno da temática da desigualdade ambiental e da justiça ambiental no meio acadêmico e científico brasileiro (ACSELRAD; HERCULANO; PÁDUA, 2004).

\section{Breve discussão sobre o conceito de desigualdade ambiental}

Desigualdade ambiental pode ser definida como a exposição diferenciada de indivíduos e grupos sociais a amenidades e riscos ambientais. Ou seja, os indivíduos não são iguais do ponto de vista do acesso a bens e amenidades ambientais (tais como ar puro, áreas verdes e água limpa), assim como em relação à sua exposição a riscos ambientais (enchentes, deslizamentos e poluição). Dessa forma, fatores como localização do domicílio, qualidade da moradia e disponibilidade de meios de transporte podem limitar o acesso a bens ambientais, bem como aumentar a exposição a riscos ambientais (TORRES, 1997).

Outra maneira de conceber a desigualdade ambiental é relacioná-la com outras formas de desigualdade presentes na sociedade, tais como entre raças, sexos, grupos de renda, etc. Neste caso, os indivíduos são desiguais ambientalmente porque são desiguais de outras maneiras. Neste sentido, a idéia de desigualdade ambiental implica o sentido de sobreposição ou exposição simultânea a mais de uma forma de desigualdade, além da ambiental, tais como a desigualdade social, econômica, residencial, de raça, etc. (TORRES, 1997).

Assim, nesta perspectiva, a desigualdade ambiental implica uma espécie de sofrimento adicional, que caracteriza certas situações de desigualdade. Por exemplo, uma família de baixa renda residente numa favela, além do sofrimento derivado das más condições de habitação, da ausência de recursos, etc., pode estar adicionalmente exposta a riscos ambientais, tais como inundações, desabamentos, etc.

Taschner (2000) desenvolve reflexões sistemáticas a respeito do que ela identificou como sendo "favelas em situação de risco ambiental". Trata-se de uma formulação bem próxima da desigualdade ambiental, porque se refere a determina- 
dos grupos populacionais particularmente marginalizados (os favelados), que seriam também adicionalmente afetados pelo risco ambiental. Nesse sentido, cabe destacar que, nas duas últimas décadas, tem ocorrido um forte processo de expansão e periferização das favelas no município de São Paulo, que, em geral, ocupam áreas públicas, muitas vezes localizadas em fundos de vale e beiras de córregos, com risco de enchentes, ou em encostas com declividades acentuadas, com alta propensão à erosão, configurando-se situações de desigualdade ambiental (TORRES; MARQUES, 2001; 2002).

Formulações semelhantes à desigualdade ambiental também podem ser observadas em Hogan (1993), que estudou as diferenças entre os residentes na poluída Cubatão e os migrantes pendulares que trabalham diariamente nas empresas da região. Os moradores apresentaram condições socioeconômicas significativamente piores do que os migrantes, segundo todos os indicadores considerados (renda, emprego, escolaridade, etc.). Além disso, esta população residente era predominantemente não-branca e de origem nordestina.

Para Jacobi (1995), há uma relação direta entre exposição a riscos ambientais e precariedade de acesso a serviços públicos. A própria ausência de infra-estrutura urbana (água, esgoto, coleta de lixo, canalização de córregos, etc.) expõe as populações residentes nestas áreas a riscos ambientais, como as doenças de veiculação hídrica.

Estes estudos da literatura sociológica e demográfica brasileira são exemplos de formulações que se aproximam do conceito de desigualdade ambiental, no sentido da sobreposição de mazelas sociais e ambientais: pobreza, má qualidade construtiva dos domicílios, problemas sanitários, altos níveis de poluição do ar, deslizamentos, enchentes, etc.

Há, portanto, uma tendência de os grupos de baixa renda residirem em áreas com más condições urbanísticas e sanitárias e em situações de risco e degradação ambiental (como, por exemplo, terrenos próximos de cursos d'água e de lixões ou com alta declividade). A explicação mais geral é que estas áreas são as únicas acessíveis à população mais pobre, seja porque tratase de áreas públicas e/ou de preservação (invadidas), seja porque são muito desvalorizadas no mercado de terras, por serem pouco propícias à ocupação, devido às características de risco e à falta de infraestrutura urbana (ALVES, 2006).

Nesse sentido, um aspecto importante sobre a desigualdade ambiental diz respeito à origem do fenômeno, com duas correntes principais de explicação para o seu surgimento. A primeira afirma que a desigualdade ambiental tem origem no mercado de terras. Segundo esta corrente, minorias e famílias de baixa renda se instalariam "voluntariamente" em áreas onde já existiam previamente problemas e riscos ambientais, devido ao baixo preço da terra vigente nestas localidades (NAPTON; DAY, 1992).

Já uma segunda corrente de explicação defende que são os mecanismos institucionais que geram a desigualdade ambiental. Neste caso, a ação do Estado e de grupos sociais e econômicos mais ricos e poderosos induziria a instalação de atividades geradoras de risco e degradação ambiental (lixões, indústrias poluidoras, incineradores) em áreas já previamente habitadas por minorias e comunidades de baixa renda, as quais teriam baixa capacidade de resistência à instalação dessas atividades (BULLARD, 1990; PULIDO, 2000).

Em última análise, esse debate gira em torno da causalidade do fenômeno, ou seja, de quem se instalou primeiro ("which came first"): as minorias/comunidades de baixa renda ou as fontes de risco e degradação ambiental. $\mathrm{Na}$ realidade, os dois tipos de origem da desigualdade ambiental podem ocorrer. Existem tanto situações em que o risco ambiental já está presente e as famílias "optam" por se localizar nessas áreas, quanto aquelas em que comunidades previamente instaladas são "assaltadas" por empreendimentos causadores de risco, poluição e degradação ambiental, cuja instalação foi definida em instâncias institucionais fora do controle dessas comunidades (PASTOR; SADD; HIPP, 2001; KRIEG, 1998).

Diversas vezes, os termos "desigualdade ambiental" e "(in)justiça ambiental" 
são empregados como sinônimos, o que reflete a proximidade entre estes dois conceitos. A injustiça ambiental pode ser definida, de uma maneira bastante ampla, como uma iniqüidade, percebida ou real, resultante da distribuição desigual de externalidades ambientais, as quais recaem de maneira desproporcional sobre comunidades de minorias e de grupos de baixa renda. Por conseqüência, justiça ambiental (ou eqüidade ambiental) pode ser definida como a diminuição ou mitigação dessas injustiças ambientais (MOST; SENGUPTA; BURGENER, 2004; HOLIFIELD, 2001).

Segundo Herculano (2002),

justiça ambiental é o conjunto de princípios que asseguram que nenhum grupo de pessoas, sejam raciais ou de classe, suporte uma parcela desproporcional das conseqüências ambientais negativas de operações econômicas ou de políticas e programas, bem como conseqüências resultantes da ausência ou omissão de tais políticas. Ou seja, justiça ambiental é o princípio em que os custos ambientais devem ser distribuídos de maneira justa entre a sociedade. Por outro lado, injustiça ambiental é o mecanismo pelo qual sociedades desiguais destinam a maior carga dos danos ambientais a grupos sociais de trabalhadores, populações de baixa renda, grupos raciais marginalizados e demais grupos vulneráveis.

O conceito de justiça ambiental nasceu no final da década de 70, nos Estados Unidos, em movimentos sociais de negros, índios, latinos e populações de baixa renda, vizinhos de depósitos de lixo e radioativos e de indústrias com efluentes poluentes. Naquele país, a agenda de pesquisa em torno do tema da justiça ambiental é muito ampla, com forte crescimento nos últimos 30 anos, tendo atualmente uma influência importante na política ambiental norte-americana. Um caso paradigmático foi o decreto assinado pelo presidente Bill Clinton, em 1994, que assegura assistência do governo federal a comunidades de minorias e de grupos de baixa renda contra as eventuais conseqüências da maior exposição dessas comunidades a externalidades ambientais (CUTTER, 1995; BUZZELI et al., 2003).

No Brasil, a agenda de pesquisa em torno da temática da justiça ambiental ainda é relativamente incipiente, com destaque para a atuação da Rede Brasileira de Justiça Ambiental (ACSELRAD; HERCULANO; PÁDUA, 2004). Assim, o desenvolvimento de estudos para operacionalização empírica dos conceitos de desigualdade ambiental e justiça ambiental deve ser parte importante da agenda para o avanço da pesquisa em torno dessa temática, no meio acadêmico e científico brasileiro.

\section{Metodologia}

A metodologia geral do trabalho é a construção de um Sistema de Informação Geográfica (SIG), através do qual as cartografias digitais (layers) das áreas de risco ambiental (áreas próximas de cursos d'água e áreas com altas declividades) são sobrepostas às malhas digitais dos setores censitários e áreas de ponderação do município de São Paulo, dos Censos Demográficos do IBGE de 1991 e 2000 . $^{1}$

A cartografia digital da rede hidrográfica possui uma escala espacial bastante detaIhada, abrangendo todos os rios e represas de médio e grande portes e a maioria dos córregos do município. Por meio desta cartografia, é possível identificar as áreas localizadas muito próximas (menos de 50 metros) e/ou às margens dos cursos d'água (rios, represas e córregos), consideradas, neste trabalho, áreas de risco ambiental, ou seja, que apresentam risco de enchentes e/ou de doenças de veiculação hídrica e outras associadas à contaminação da água e poluição do meio ambiente. ${ }^{2}$

Já a superfície de declividade do município de São Paulo foi gerada a partir de um Modelo Digital de Elevação, que, por

\footnotetext{
${ }^{1}$ Cabe ressaltar que esta metodologia empregada na análise de situações de risco ambiental associado à proximidade de cursos d'água e a altas declividades também pode ser utilizada para o estudo de outras modalidades de risco ambiental, tais como populações residentes em áreas contaminadas, próximas de lixões, áreas de preservação ambiental, etc.

2 Para estimar a população residente em áreas à beira de cursos d'água, foram gerados buffers (bandas) de 50 metros, nas duas margens de todos os cursos d'água e feita a sobreposição destes buffers aos setores censitários do município de São Paulo.
} 
sua vez, foi criado através da interpolação das curvas de nível das cartas topográficas do município (distância de cinco metros). A partir da superfície de declividade, selecionaram-se as áreas com altas declividades. Estão sendo consideradas altas declividades as áreas com declividade superior a $30 \%$, que, como se sabe, apresentam risco de deslizamento e escorregamento.

Assim, inicialmente foram identificadas as áreas de risco ambiental - aquelas muito próximas de cursos d'água (menos de 50 metros) e/ou com altas declividades (mais de $30 \%$ ), ou seja, áreas com riscos de enchentes e de deslizamentos. Posteriormente, por meio da sobreposição das cartografias digitais das áreas de risco ambiental (próximas de cursos d'água e com alta declividade) às malhas digitais dos setores censitários de 1991 e 2000, foram estimados o tamanho da população, o crescimento demográfico e as características socioeconômicas dos residentes dentro e fora das áreas de risco ambiental, nas duas datas censitárias. Estas estimativas foram feitas tanto para o conjunto do município como para cada uma das regiões delimitadas pela distribuição espacial dos grupos sociais do município de São Paulo (pobres, classe média e classe alta).

Para a realização destas estimativas, utilizou-se um método de geoprocessamento conhecido como overlayer, que pode ser traduzido como "sobreposição de cartografias" e que permite estimar a população residente, em 1991 e 2000, em áreas de risco ambiental, atribuindo a estas áreas os dados demográficos e socioeconômicos dos setores censitários sobrepostos a elas, na proporção em que os territórios daqueles setores participam do território das áreas de risco. ${ }^{3}$

As três regiões, correspondentes aos três grandes grupos sociais presentes na metrópole de São Paulo, foram definidas por Marques (2005), com base em análises multivariadas (fatorial e de agrupamentos), partindo inicialmente de um amplo conjunto de variáveis socioeconômicas e demográficas da amostra do Censo 2000. Ao final da análise fatorial, foram selecionadas apenas duas variáveis - renda domiciliar média e taxa de crescimento demográfico da área de ponderação entre 1991 e 2000 -, que foram utilizadas na análise de agrupamentos para delimitar os três grupos sociais. Desta maneira, o conjunto de 456 áreas de ponderação do município São Paulo foi estratificado segundo três grandes grupos de regiões, correspondentes aos três grupos sociais: "regiões pobres", com predomínio de população de baixa renda; "regiões de classe média", com predomínio de população de classe média; e "regiões de classe alta", com predomínio de população de alta renda (MARQUES, 2005; MARQUES; TORRES, 2005). ${ }^{4}$

\section{Aumento da desigualdade ambiental em São Paulo: crescimento populacional diferenciado dos grupos sociais expostos a situações de risco ambiental}

Inicialmente, será analisada a evolução da população residente em áreas de risco ambiental, entre 1991 e 2000, para verificar se a desigualdade ambiental está ou não aumentando no município de São Paulo, no período recente. Para isso, estimou-se, por meio do método de overlayer, a população residente, em 1991 e 2000, em áreas de risco ambiental, ou seja, naquelas muito próximas de cursos d'água (menos de 50 metros) e/ou com alta declividade (mais de $30 \%)$.

As estimativas obtidas pelo método overlayer apontam para uma população de 1,6 milhão de pessoas residindo em áreas

\footnotetext{
3 Portanto, mais do que um recurso de visualização de sobreposição cartográfica, o overlayer é um instrumento que permite estimar, para as áreas de risco ambiental (no caso, aquelas próximas de cursos d'água e/ou com alta declividade), informações tais como a população e o número de domicílios que [antes] eram atributos dos setores censitários. Ao utilizar o overlayer, assume-se que a distribuição da população é homogênea ao longo da área que é a fonte da informação populacional, no caso o setor censitário.

${ }^{4}$ Para maiores detalhes sobre os conceitos e metodologias empregados para a delimitação dos grupos sociais presentes na metrópole de São Paulo, ver Marques (2005) e Marques e Torres (2005).
} 
de risco ambiental, no município de São Paulo, em 1991. Como a população total do município correspondia a 9,6 milhões de pessoas naquele ano, as áreas de risco ambiental eram residência de $16,5 \%$ dos habitantes do município.

Em 2000, as pessoas residindo em áreas de risco ambiental eram quase $2 \mathrm{mi}$ Ihões, enquanto a população do município correspondia a 10,4 milhões. Assim, a participação dos residentes em áreas de risco chegou a $19,1 \%$ dos habitantes da capital paulista, naquele ano. $\mathrm{O}$ aumento da participação da população residente em áreas de risco ambiental (próximas de cursos d'água e/ou com alta declividade) na população total do município é decorrente do fato de que, enquanto nestas áreas de risco a taxa de crescimento populacional foi de $2,5 \%$ ao ano, nas demais áreas atingiu apenas 0,5\% ao ano, entre 1991 e 2000.

Portanto, os resultados revelam que 1 em cada 5 habitantes do município de São Paulo (o equivalente a quase 2 milhões de pessoas) reside em áreas de risco ambiental, ou seja, em localidades muito próximas de cursos d'água (risco de enchentes e contato com doenças de veiculação hídrica) e/ou naquelas com alta declividade (risco de deslizamento).

Porém, apesar de expressivos, estes resultados são distorcidos pelo fato de as maiores concentrações de áreas de risco ambiental estarem localizadas nas regiões pobres e periféricas do município de São Paulo. Isto significa que, ao se observar o crescimento populacional do conjunto de áreas de risco, não se têm condições de discernir se este crescimento é derivado das características propriamente ambientais destas áreas, ou do fato de que este tipo de área está mais concentrado nas regiões pobres e periféricas da cidade. ${ }^{5}$
Assim, com o objetivo de eliminar o efeito do crescimento populacional da periferia nos dados de incremento da população residente em áreas de risco ambiental (agregados para o conjunto do município), foram realizadas análises comparativas entre áreas de risco e de não-risco, para cada um dos três grupos de regiões: "regiões pobres", com predomínio de população de baixa renda; "regiões de classe média", com predomínio de população de classe média; e "regiões de classe alta", com predomínio de população de alta renda (MARQUES, 2005).

Em cada uma das regiões, estimou-se, para as áreas de risco e as de não-risco, o tamanho da população, nas duas datas censitárias (1991 e 2000). Em seguida calculouse a taxa de crescimento populacional entre as duas datas (Tabelas 1 e 2). O Mapa 1 mostra a distribuição espacial das áreas de risco ambiental (próximas de cursos d'água e/ou com alta declividade) e dos três grupos de regiões (pobres, classe média e classe alta) no município de São Paulo.

No conjunto de "regiões pobres" do município, ou seja, onde predomina população de baixa renda, a proporção de pessoas vivendo em áreas de risco ambiental chega a expressivos $28,3 \%$, em 2000 , o que representa um contingente populacional de 1,1 milhão de pessoas residindo em áreas com sobreposição cumulativa de pobreza e risco ambiental. Já nas "regiões de classe média" e "regiões de classe alta", as proporções de população vivendo em áreas de risco ambiental são bem menores, com respectivamente $14,8 \%$ e $9,9 \%$ (Tabela 1 ).

Além disso, os resultados também mostram que, nos três grupos de regiões, a população cresceu mais rapidamente nas áreas de risco ambiental (próximas de cursos d'água e/ou com alta declividade), entre

\footnotetext{
${ }^{5}$ Portanto, é preciso cautela na interpretação do crescimento populacional das áreas de risco ambiental, quando os dados estão agregados para o conjunto do município de São Paulo. Isto porque a população residente em áreas próximas de cursos d'água e/ou com alta declividade está desproporcionalmente concentrada em regiões pobres e periféricas da cidade. Assim, de forma agregada, não é possível saber se o crescimento populacional das áreas de risco ambiental é real ou apenas um efeito secundário do maior incremento populacional da periferia. Para observar o crescimento demográfico efetivamente ocorrido nas áreas de risco ambiental, é necessário também verificar o que se passa nos diversos tipos de regiões do município de São Paulo, com o objetivo de eliminar o efeito do crescimento da população das regiões pobres e periféricas, nos dados de expansão da população em áreas de risco, agregados para o conjunto do município. Interpretações incorretas de relações observadas a partir de dados agregados muitas vezes decorrem de um problema chamado falácia ecológica.
} 
TABELA 1

Tamanho e participação relativa da população, por regiões, segundo áreas de risco e de não-risco ambiental Município de São Paulo - 1991-2000

\begin{tabular}{|c|c|c|c|c|c|c|c|c|}
\hline \multirow[b]{2}{*}{ Áreas } & \multicolumn{4}{|c|}{1991} & \multicolumn{4}{|c|}{2000} \\
\hline & $\begin{array}{l}\text { Total do } \\
\text { município }\end{array}$ & $\begin{array}{l}\text { Regiões } \\
\text { pobres }\end{array}$ & $\begin{array}{c}\text { Regióes } \\
\text { de classe } \\
\text { média }\end{array}$ & $\begin{array}{c}\text { Regiões } \\
\text { de classe } \\
\text { alta }\end{array}$ & $\begin{array}{l}\text { Total do } \\
\text { município }\end{array}$ & $\begin{array}{c}\text { Regiões } \\
\text { pobres }\end{array}$ & $\begin{array}{c}\text { Regióes } \\
\text { de classe } \\
\text { média }\end{array}$ & $\begin{array}{l}\text { Regiões de } \\
\text { classe alta }\end{array}$ \\
\hline \multicolumn{9}{|c|}{ Tamanho da população } \\
\hline Total & 9.644 .122 & 2.799 .606 & 5.198 .973 & 1.644 .240 & 10.434 .252 & 3.873.362 & 5.074 .262 & 1.486 .628 \\
\hline Áreas de risco & 1.593 .591 & 717.645 & 712.089 & 163.855 & 1.991 .716 & 1.095 .621 & 749.052 & 147.043 \\
\hline Áreas de não-risco & 8.050 .531 & 2.081 .961 & 4.486 .884 & 1.480 .385 & 8.442 .536 & 2.777 .741 & 4.325 .210 & 1.339 .585 \\
\hline \multicolumn{9}{|l|}{ Participação (em \%) } \\
\hline Total & 100,00 & 100,00 & 100,00 & 100,00 & 100,00 & 100,00 & 100,00 & 100,00 \\
\hline Áreas de risco & 16,52 & 25,63 & 13,70 & 9,97 & 19,09 & 28,29 & 14,76 & 9,89 \\
\hline Áreas de não-risco & 83,48 & 74,37 & 86,30 & 90,03 & 80,91 & 71,71 & 85,24 & 90,11 \\
\hline
\end{tabular}

TABELA 2

Taxas geométricas de crescimento anual da população, por regiões, segundo áreas de risco e de não-risco ambiental Município de São Paulo - 1991/2000

Em porcentagem

\begin{tabular}{lcccc}
\hline Áreas & $\begin{array}{c}\text { Total } \\
\text { do município }\end{array}$ & $\begin{array}{c}\text { Regiões } \\
\text { pobres }\end{array}$ & $\begin{array}{c}\text { Regiões } \\
\text { de classe média }\end{array}$ & $\begin{array}{c}\text { Regiões } \\
\text { de classe alta }\end{array}$ \\
\hline Áreas de risco ambiental & 2,51 & 4,81 & 0,56 & $-1,20$ \\
Áreas de não-risco ambiental & 0,53 & 3,26 & $-0,41$ & $-1,10$ \\
Total & $\mathbf{0 , 8 8}$ & $\mathbf{3 , 6 7}$ & $\mathbf{- 0 , 2 7}$ & $\mathbf{- 1 , 1 1}$ \\
\hline
\end{tabular}

Fonte: IBGE. Censos Demográficos de 1991 e 2000; CEM-Cebrap, cartografias das áreas de risco ambiental; Marques (2005).

1991 e 2000. Assim, nas regiões pobres e periféricas, a população em áreas de risco cresceu $4,8 \%$ ao ano, enquanto fora destas áreas o ritmo foi bem menor (3,3\% a.a.). Nas regiões de classe média, os residentes em áreas de risco ambiental registraram expansão de $0,6 \%$ a.a., enquanto naquelas de não-risco a população decresceu $0,4 \%$ ao ano, no período 1991-2000. Já nas regiões de classe alta, a população diminuiu a taxas muito semelhantes nas áreas de risco e de não-risco (Tabela 2).

Como as regiões de classe alta (inclusive nas áreas de risco) tiveram crescimento populacional negativo e as áreas de risco ambiental das regiões de classe média apresentaram aumento de apenas 0,6\% a.a., quase todo o incremento populacional das áreas de risco ambiental (próximas de cursos d'água e/ou com alta declividade) do município de São Paulo ocorreu em regiões pobres e periféricas.

Assim, enquanto a população das regiões pobres e periféricas cresce a taxas elevadas, aquela residente em áreas de risco ambiental na periferia se expande a taxas elevadíssimas. Além disso, as áreas de risco ambiental na periferia são, de modo geral, menos urbanizadas do que as áreas de risco localizadas em regióes mais ricas e centrais. Em outras palavras, as localidades à beira de cursos d'água e/ou com alta declividade, situadas nas periferias, muitas vezes em áreas menos urbanizadas e por isso mesmo duplamente sujeitas a riscos ambientais, apresentaram taxas de crescimento explosivas na década de 90.

Em síntese, os resultados mostram que as áreas onde a população de São Paulo está crescendo mais significativamente são simultaneamente áreas de risco ambiental e áreas pobres e periféricas. Este fenômeno revela um expressivo aumento da desigualdade ambiental, no município de São Paulo, no período recente.

A seguir, são levantados alguns possíveis fatores explicativos para o elevado crescimento da população residente em 
MAPA 1

Distribuição espacial das áreas de risco ambiental (próximas de cursos d'água e/ou com alta declividade) e dos três grupos de regiões (pobres, classe média e classe alta) Município de São Paulo - 2000

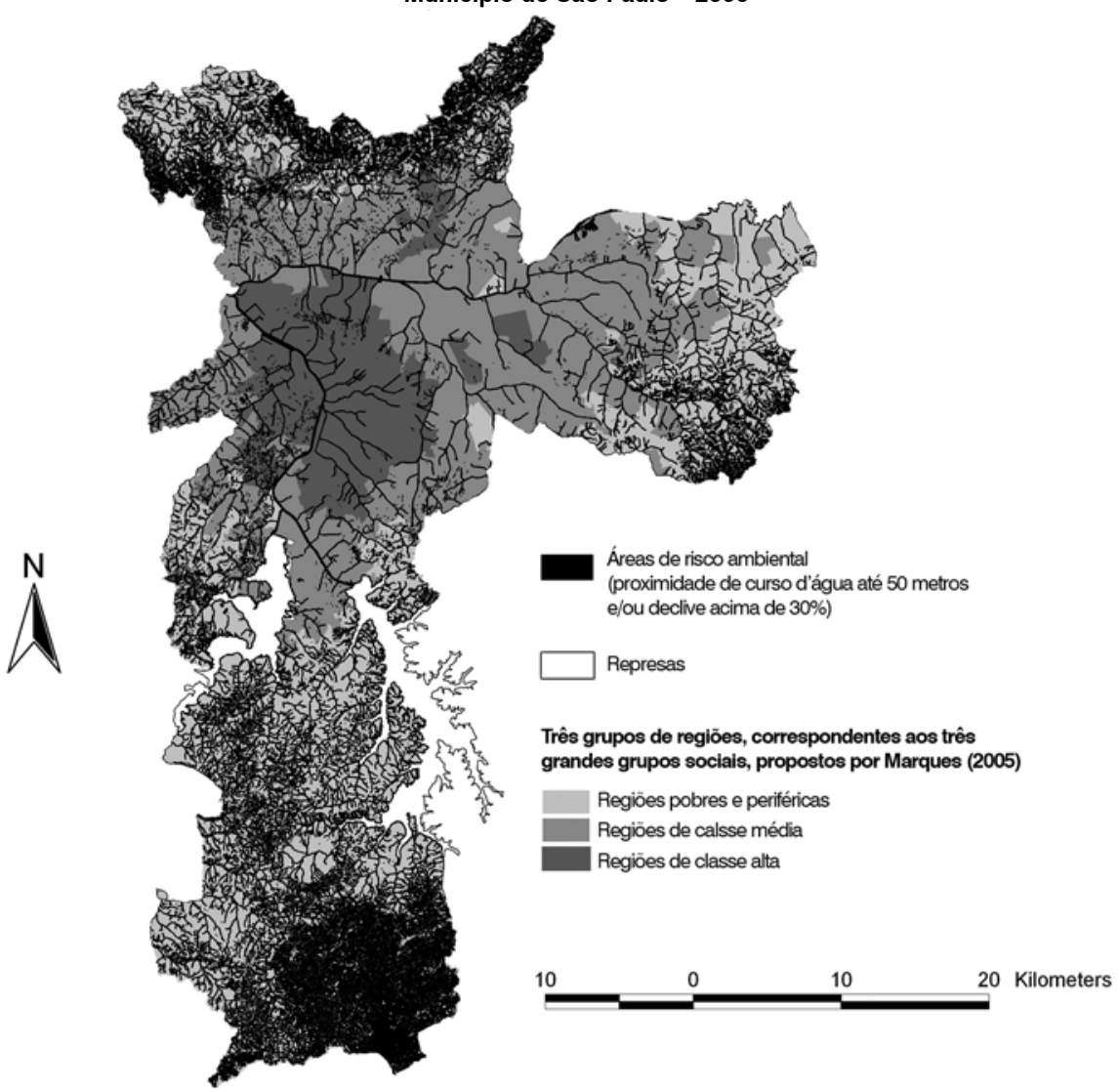

Fonte: CEM-Cebrap, cartografias das áreas de risco ambiental; Marques (2005).

áreas de risco ambiental (próximas de cursos d'água e/ou com alta declividade), no município de São Paulo, notadamente em regiões pobres e periféricas.

Um primeiro fator está ligado ao fato de que o crescimento do município de São Paulo, bem como de toda a região metropolitana, continua a se pautar pela expansão horizontal e pelo processo de periferização (TORRES, 2005). As periferias do município e da Região Metropolitana de São Paulo, especialmente em seus extremos norte, sul e leste, apresentam uma rede bastante densa de cursos d'água, devido à sua própria situação topográfica e hidrológica de cabeceiras de bacias hidrográficas. Além disso, as áreas periféricas também avançam sobre as regiões montanhosas, com topografia acidentada, como a Serra da Cantareira. Assim, o simples fato de que as taxas de crescimento populacional sejam mais elevadas nestas áreas implica, necessariamente, o aumento mais acelerado da população em áreas de risco ambiental. ${ }^{6}$

\footnotetext{
6 Porém, cabe reafirmar que, no interior das regiões pobres e periféricas, a população residente em áreas de risco ambiental cresceu ainda mais rapidamente do que a população em geral, durante a década de 90 . Em outras palavras, o crescimento das periferias explica apenas parcialmente o intenso aumento populacional das áreas de risco associado à proximidade de cursos d'água e a altas declividades, no município de São Paulo.
} 
Um segundo fator explicativo tem a ver com a própria dinâmica de ocupação das terras urbanas. Como a malha urbana do município de São Paulo, inclusive nas regiões periféricas mais consolidadas, já se encontra em grande parte ocupada, é plausível que a continuidade do crescimento horizontal implique a ocupação de áreas menos próprias para assentamento humano, tais como as próximas de cursos d'água e aquelas com alta declividade. Estas áreas de risco ambiental, muitas vezes, são as únicas acessíveis à população de mais baixa renda, por serem áreas públicas e/ou de preservação (invadidas), ou por serem localidades muito desvalorizadas no mercado de terras, devido às características de risco e falta de infraestrutura urbana (ALVES, 2006). ${ }^{7}$

Ainda um terceiro fator está relacionado ao expressivo crescimento da população residente em favelas. A associação entre favelas e áreas de risco ambiental, principalmente aquelas à beira de cursos d'água, mas também as com alta declividade, é bastante evidente na literatura sobre o tema (TASCHNER, 2000).

Em síntese, as condições naturais das áreas onde tem ocorrido crescimento populacional, o esgotamento das áreas disponíveis para o crescimento urbano horizontal e o aumento da população favelada são alguns fatores explicativos para o expressivo incremento populacional das áreas de risco ambiental, no município de São Paulo, no período recente.

\section{Associação entre pior condição socioeconômica e risco ambiental em São Paulo}

Uma vez constatado o aumento das situações de desigualdade ambiental no município de São Paulo no período recente, ${ }^{8}$ passa-se, agora, a verificar a hipótese da existência de associação positiva entre piores condições socioeconômicas e maior exposição a risco ambiental. Como mencionado anteriormente, uma das hipóteses da desigualdade ambiental é de que os riscos ambientais são distribuídos desigualmente, assim como a renda e o acesso a serviços públicos.

Já se observou, no item anterior, que a proporção de pessoas vivendo em áreas de risco ambiental é bem mais alta nas regiões pobres $(28,3 \%)$ do que nas de classe média $(14,8 \%)$ e de classe alta $(9,9 \%)$ (Tabela 1$)$. Além disso, considerando-se somente a distribuição da população residente em áreas de risco ambiental, segundo tipo de região, em 2000 , verifica-se que $55 \%$ encontramse em regiões pobres, $37,6 \%$ naquelas de classe média e apenas $7,4 \%$ em regiões de classe alta (Tabela 3). ${ }^{9}$

TABELA 3

Distribuição da população residente, por regiões, segundo áreas de risco e de não-risco ambiental Município de São Paulo - 2000

\begin{tabular}{lcccc}
\hline Áreas & $\begin{array}{c}\text { Regiões } \\
\text { pobres }\end{array}$ & $\begin{array}{c}\text { Regiões } \\
\text { de classe média }\end{array}$ & $\begin{array}{c}\text { Regiões } \\
\text { de classe alta }\end{array}$ & $\begin{array}{c}\text { Total } \\
\text { do município }\end{array}$ \\
\hline Áreas de risco & 55,01 & 37,61 & 7,38 & 100,00 \\
Áreas de não-risco & 32,90 & 51,23 & 15,87 & 100,00 \\
Total & $\mathbf{3 7 , 1 2}$ & $\mathbf{4 8 , 6 3}$ & $\mathbf{1 4 , 2 5}$ & $\mathbf{1 0 0 , 0 0}$ \\
\hline
\end{tabular}

Fonte: IBGE. Censo Demográfico de 2000; CEM-Cebrap, cartografias das áreas de risco ambiental; Marques (2005).

\footnotetext{
${ }^{7}$ No município de São Paulo, grande parte das terras disponíveis para eventual expansão da ocupação horizontal constitui ou áreas públicas e de preservação, ou terrenos menos próprios para ocupação, devido às suas condições naturais próximos de cursos d'água, altas declividades sujeitas a deslizamentos, etc. Isto significa que, na ausência de uma política habitacional que contribua para o adensamento das áreas já ocupadas, o crescimento populacional, principalmente nas regiões periféricas, venha a implicar a ocupação de áreas de risco ambiental.

8 Como vimos, o aumento da desigualdade ambiental foi verificado através da constatação de que as áreas onde a população de São Paulo está crescendo mais significativamente são simultaneamente áreas de risco ambiental e áreas pobres e periféricas.

${ }^{9}$ A distribuição relativa da população em áreas de risco, segundo tipo de região, apresentada na Tabela 3, foi calculada a partir dos números absolutos constantes da Tabela 1.
} 
Estes números já corroboram a hipótese de exposição diferenciada dos grupos sociais ao risco ambiental, uma vez que a exposição ao risco é bem maior nas regiões pobres, com predomínio de população de baixa renda, do que naquelas com predomínio de populações de classes média e alta.

Porém, para testar a hipótese da existência de associação positiva entre piores condições socioeconômicas e maior exposição a risco ambiental, será feita, a seguir, uma análise comparativa dos indicadores socioeconômicos e demográficos entre as áreas de risco ambiental e as de não-risco, tanto para o conjunto do município de São Paulo como para cada uma das três regiões.

Inicialmente, compararam-se as condições de saneamento básico das áreas de risco e de não-risco ambiental, para o conjunto do município de São Paulo, em 2000. No que se refere às coberturas da rede de abastecimento de água e da coleta de lixo, observa-se, na Tabela 4, que são pequenas as diferenças de cobertura entre as áreas de risco ambiental (próximas de cursos d'água e/ou com alta declividade) e aquelas de não-risco (distantes de cursos d'água e com baixa declividade). ${ }^{10}$

Porém, o mesmo não pode ser dito em relação à cobertura de esgoto, que revela grandes desigualdades entre os dois tipos de área. Assim, enquanto nas áreas de não-risco (distantes de cursos d'água e com baixa declividade) $90,6 \%$ dos domicílios estavam ligados à rede de esgoto, naquelas de risco ambiental (próximas de cursos d'água e/ou com alta declividade) esta proporção era de apenas $71,9 \%$, o que indica uma baixa cobertura de esgoto em muitas áreas à beira de cursos d'água e/ou com alta declividade (Tabela 4). ${ }^{11}$

Os indicadores de renda também são bastante discrepantes entre as áreas de risco ambiental e as de não-risco, no conjunto do município de São Paulo. Na Tabela 4 , verifica-se que a renda média mensal dos chefes de domicílio, no conjunto de áreas de risco ambiental, correspondia a 888 reais (5,9 salários mínimos), em 2000, enquanto nas áreas de não-risco ambiental esse valor chegava a 1.421 reais $(9,4$ salários mínimos). Já a proporção de responsáveis pelo domicílio com baixa renda (inferior a três salários mínimos, inclusive os sem rendimento) variava de $37,5 \%$, no conjunto de áreas de não-risco, a 51,8\%, naquelas de risco ambiental.

A comparação entre os indicadores de escolaridade também pode ser vista na Tabela 4. Em 2000, a proporção de responsáveis pelo domicílio com baixa escolaridade (até três anos de estudo, inclusive os sem instrução) chegava a $24,1 \%$ nas áreas de risco ambiental (até 50 metros de cursos d'água e/ou declividade acima de $30 \%$ ), contra apenas $16,4 \%$ naquelas de não-risco ambiental. Por outro lado, os chefes de domicílio com ensino superior completo correspondiam a $19,3 \%$ nas áreas de não-risco (distantes de cursos d'água e com baixa declividade) e apenas $10 \%$ nas de risco ambiental. Com isso, o número médio de anos de estudo dos responsáveis pelo domicílio variava de 6,4 anos, nas áreas de risco ambiental, a 7,9 anos, nas de não-risco.

Com relação à estrutura etária da população, verifica-se que as áreas de risco ambiental (próximas de cursos d'água e/ ou com alta declividade) possuíam, em 2000, uma concentração significativamente maior de crianças e jovens do que aquelas de não-risco ambiental. Assim, enquanto nestas últimas a proporção de crianças de zero a quatro anos de idade era de apenas $8 \%$, nas áreas de risco ambiental chegava a $10,3 \% .{ }^{12}$ Já o segmento de crianças e jovens

\footnotetext{
10 Estas pequenas diferenças entre as áreas de risco e as de não-risco ambiental devem-se ao fato de as coberturas de abastecimento de água e de coleta de lixo estarem praticamente universalizadas no município de São Paulo, o que não ocorre com a coleta de esgoto.

$11 \mathrm{Na}$ realidade, a porcentagem de cobertura de esgoto é mais baixa nas áreas próximas de cursos d'água do que naquelas com alta declividade, com, respectivamente, $70,7 \%$ e $73,1 \%$.

12 Como se sabe, as crianças de zero a quatro anos são as mais vulneráveis a doenças de veiculação hídrica, o que reforça a situação de vulnerabilidade e desigualdade ambiental das áreas à beira dos cursos d'água.
} 
de zero a 14 anos correspondia a $23,8 \%$ da população, nas áreas de não-risco ambiental, e a $29,2 \%$, naquelas de risco ambiental. A proporção de idosos (65 anos ou mais) também variava significativamente entre as áreas de risco $(4,1 \%)$ e as de não-risco ambiental (7,0\%).

Como visto anteriormente, a associação entre favelas e áreas de risco ambiental é recorrente na literatura sobre o tema (TASCHNER, 2000). Assim, comparandose os percentuais de população residente em setores subnormais (áreas de favela segundo definição IBGE), para o conjunto do município de São Paulo, constata-se que, enquanto nas áreas de não-risco apenas $5,7 \%$ da população residia em setores subnormais, nas de risco ambiental (próximas de cursos d'água e/ou com alta declividade) esta porcentagem chegava a expressivos $21,6 \%$ (Tabela 4).

Em resumo, os resultados para o conjunto do município de São Paulo revelam que os residentes em áreas de risco ambiental (próximas de cursos d’água e/ou com altas declividades) apresentam condições socioeconômicas bastante piores, além de maior concentração de crianças e jovens, do que a população moradora fora destas áreas.

Porém, apesar de expressivos, os resultados desta análise, para o conjunto do município, são distorcidos pelo fato de as populações residentes em áreas de risco ambiental estarem desproporcionalmente concentradas nas regiões pobres e periféricas do município de São Paulo. Por esta razão, ao se compararem as áreas de risco ambiental com aquelas de não-risco, para o conjunto do município, não é possível discernir plenamente se as condições socioeconômicas das áreas de risco estão relacionadas às características propriamente ambientais destas localidades, ou se são apenas conseqüência do fato de estarem mais concentradas nas regiões pobres e periféricas da cidade.

Para contornar este problema, conhecido por falácia ecológica, foram realizadas análises comparativas entre as áreas de

TABELA 4

Comparação dos indicadores socioeconômicos e demográficos, por áreas de risco e de não-risco ambiental Município de São Paulo - 2000

\begin{tabular}{lccc}
\hline Indicadores & $\begin{array}{c}\text { Áreas de risco Áreas de não-risco } \\
\text { ambiental } \\
\text { ambiental }\end{array}$ & $\begin{array}{c}\text { Total do } \\
\text { município }\end{array}$ \\
\hline Cobertura da rede de água (\%) & 96,90 & 99,00 & 98,62 \\
Cobertura da rede de esgoto (\%) & 71,94 & 90,58 & 87,23 \\
Coleta de lixo (\%) & 97,76 & 99,51 & 99,20 \\
Chefes de domicílio analfabetos (\%) & 8,95 & 5,19 & 5,86 \\
Chefes de domicílio com baixa escolaridade (até 3 anos de & 24,09 & 16,41 & 17,78 \\
estudo, inclusive sem instrução) (\%) & 10,03 & 19,25 & 17,60 \\
Chefes de domicílio com ensino superior completo (\%) & 6,44 & 7,94 & 7,67 \\
Número médio de anos de estudo do chefe de domić́lio (em anos) & 51,84 & 37,48 & 40,06 \\
Chefes de domicílio com renda de 0 a 3 salários mínimos (\%) & 17,08 & 21,80 & 20,95 \\
Chefes de domicílio com renda superior a 5 salários mínimos (\%) & 888,24 & 1421,05 & 1325,43 \\
Renda média do chefe de domicílio (em reais) & 5,88 & 9,41 & 8,78 \\
Renda média do chefe de domicílio (em salários mínimos) & 10,31 & 7,98 & 8,43 \\
População de 0 a 4 anos (\%) & 29,23 & 23,81 & 24,84 \\
População de 0 a 14 anos (\%) & 4,10 & 6,97 & 6,42 \\
População de 65 anos e mais (\%) & 21,60 & 5,68 & 8,72 \\
População residente em setores subnormais (\%) & & \\
\hline Fon
\end{tabular}

Fonte: IBGE. Censo Demográfico de 2000; CEM-Cebrap, cartografias das áreas de risco ambiental. 
risco ambiental e aquelas de não-risco, controlando por tipo de grupo social, ou seja, fazendo uma análise estratificada segundo regiões pobres, regiões de classe média e regiões de classe alta, com base em Marques (2005). Os resultados mostram que, no interior de cada grupo de regiões (pobres, classe média e classe alta), repetese o mesmo padrão observado para o conjunto do município de São Paulo, isto é, as áreas de risco ambiental apresentam indicadores socioeconômicos significativamente piores do que as de não-risco. Estes resultados confirmam, portanto, a hipótese da existência de associação positiva entre piores condições socioeconômicas e maior exposição a risco ambiental.

A seguir, apresentam-se os resultados da comparação entre áreas de risco e de não-risco ambiental, apenas para o grupo de regiões pobres/periféricas de São Paulo. ${ }^{13}$

Como se sabe, no município de São Paulo, as regiões periféricas (onde se concentra população de baixa renda) apresentam condições socioeconômicas bastante piores do que as regiões mais centrais, onde predominam populações de classes média e alta (MARQUES, 2005; MARQUES; TORRES, 2005). Porém, no interior do conjunto de regiões pobres/periféricas, delimitadas pela tipologia de Marques (2005), observam-se diferenças significativas entre as áreas de risco ambiental (localizadas a até 50 metros dos cursos d'água e/ou com declividade acima de $30 \%$ ) e aquelas de não-risco (situadas a mais de 50 metros dos cursos d'água e com declividade inferior a $30 \%)$.

Em particular, a cobertura de coleta de esgoto apresenta um diferencial muito significativo entre as áreas de risco e as de não-risco, no interior das regiões pobres, com respectivamente $61,1 \%$ e $77,9 \%$ (Tabela 5). Portanto, as condições sanitárias são significativamente piores nas áreas de risco ambiental em relação àquelas de não- risco, o que confirma a associação entre risco ambiental e más condições sanitárias, principalmente nas áreas à beira de cursos d'água. ${ }^{14}$

Com relação aos indicadores de renda, também verificam-se diferenças bastante significativas entre as áreas de risco ambiental e as de não-risco, no conjunto de regiões pobres. Assim, a proporção de chefes de domicílio com baixa renda (inferior a três salários mínimos, inclusive os sem rendimento), em 2000 , correspondia a $61,8 \%$ nas áreas de risco ambiental e a $55,7 \%$ nas de não-risco (Tabela 5). Ou seja, nas regiões pobres, as áreas de risco ambiental apresentam concentração significativamente maior de chefes de domicílio com baixa renda do que naquelas de não-risco.

A alta concentração de chefes de domicílio com baixo nível de renda, nas áreas de risco ambiental, faz com que a renda média nestas áreas seja significativamente mais baixa do que naquelas de não-risco. Assim, no interior das regiões pobres, enquanto a renda média mensal dos chefes de domicílio residentes nas áreas de não-risco era de 549 reais (3,6 salários mínimos, em 2000), naquelas de risco ambiental correspondia a 475 reais ( 3,2 salários mínimos), ou seja, 75 reais mais baixa (Tabela 5 ).

Com relação à escolaridade dos responsáveis pelo domicílio, a proporção de chefes com baixa escolaridade (até três anos de estudo, inclusive os sem instrução) chegava a $29,1 \%$ nas áreas de risco ambiental, enquanto nas de não-risco era de $25,6 \%$. Já a proporção de chefes de domicílio analfabetos correspondia a $11,2 \%$ nas áreas de risco ambiental e a $9,2 \%$ naquelas de não-risco.

Por fim, no interior das regiões pobres e periféricas, a proporção de residentes em setores subnormais (favelas) alcançava mais de um quarto da população $(25,5 \%)$ nas áreas de risco ambiental, enquanto nas de não-risco era de apenas 10,5\%.

\footnotetext{
13 Para não alongar muito a descrição, não será apresentada a análise comparativa das áreas de risco e não-risco ambiental no âmbito das regiões de classe média e das regiões de classe alta. Porém, como mencionado anteriormente, nestas regiões repete-se o mesmo padrão, com as áreas de risco ambiental apresentando indicadores socioeconômicos piores do que as de não-risco.

${ }^{14}$ Nas áreas próximas de cursos d'água, no interior das regiões pobres, a porcentagem de cobertura de esgoto era de apenas $57,8 \%$.
} 
TABELA 5

Comparação dos indicadores socioeconômicos e demográficos, por áreas de risco e de não-risco ambiental Regiões pobres do município de São Paulo - 2000

\begin{tabular}{|c|c|c|c|}
\hline Indicadores & $\begin{array}{l}\text { Áreas de risco } \\
\text { ambiental }\end{array}$ & $\begin{array}{l}\text { Áreas de não- } \\
\text { risco ambiental }\end{array}$ & $\begin{array}{l}\text { Total das } \\
\text { regiões pobres }\end{array}$ \\
\hline Cobertura da rede de água (\%) & 94,75 & 97,17 & 96,50 \\
\hline Cobertura da rede de esgoto (\%) & 61,13 & 77,91 & 73,25 \\
\hline Coleta de lixo (\%) & 96,75 & 98,77 & 98,21 \\
\hline Chefes de domicílio analfabetos (\%) & 11,17 & 9,16 & 9,72 \\
\hline $\begin{array}{l}\text { Chefes de domicílio com baixa escolaridade (até } 3 \text { anos de } \\
\text { estudo, inclusive sem instrução) (\%) }\end{array}$ & 29,13 & 25,55 & 26,54 \\
\hline Chefes de domicílio com ensino superior completo (\%) & 2,77 & 3,69 & 3,44 \\
\hline Número médio de anos de estudo do chefe de domicílio (em anos) & 5,32 & 5,73 & 5,62 \\
\hline Chefes de domicílio com renda de 0 a 3 salários mínimos (\%) & 61,81 & 55,71 & 57,41 \\
\hline Chefes de domicílio com renda superior a 5 salários mínimos (\%) & 17,19 & 22,24 & 20,83 \\
\hline Renda média do chefe de domicílio (em reais) & 475,50 & 548,50 & 528,21 \\
\hline Renda média do chefe de domicílio (em salários mínimos 2000) & 3,15 & 3,63 & 3,50 \\
\hline População de 0 a 4 anos (\%) & 11,73 & 10,57 & 10,90 \\
\hline População de 0 a 14 anos (\%) & 32,72 & 30,26 & 30,96 \\
\hline População de 65 anos e mais (\%) & 2,35 & 3,03 & 2,84 \\
\hline População residente em setores subnormais (\%) & 25,45 & 10,53 & 14,75 \\
\hline
\end{tabular}

Fonte: IBGE. Censo Demográfico de 2000; CEM-Cebrap, cartografias das áreas de risco ambiental; Marques (2005).

Em resumo, os resultados para o conjunto de regiões pobres e periféricas do município de São Paulo revelam que as áreas de risco ambiental apresentam concentração significativamente maior de população com baixos níveis de renda, escolaridade e saneamento, além de maior proporção de população favelada, em comparação às áreas de não-risco..$^{15}$ Portanto, estes resultados confirmam a hipótese da existência de associação positiva entre piores condições socioeconômicas e maior exposição a risco ambiental, mesmo no interior das regiões pobres e periféricas de São Paulo.

\section{Considerações finais}

Neste trabalho, procurou-se operacionalizar empiricamente o conceito de desigual- dade ambiental, por meio da utilização de metodologias de geoprocessamento, para identificação e caracterização de situações de desigualdade ambiental no município de São Paulo. A hipótese era de que os riscos ambientais são distribuídos de maneira desigual entre os diferentes grupos sociais do município. Assim, o objetivo foi testar a existência (ou não) de associação entre piores condições socioeconômicas e maior exposição ao risco ambiental. Além disso, verificou-se se a desigualdade ambiental está ou não aumentando no município, no período recente.

Os resultados mostraram que as áreas onde a população de São Paulo cresceu mais significativamente, entre 1991 e 2000 , são, simultaneamente, áreas de risco ambiental (próximas de cursos d'água e/ou com altas declividades) e áreas pobres e periféri-

\footnotetext{
15 Como foi dito, nas regiões de classe média e de classe alta, repete-se o mesmo padrão do conjunto do município e das regiões pobres, com as áreas de risco ambiental apresentando indicadores socioeconômicos piores do que as de não-risco, o que confirma, mais uma vez, a hipótese da existência de associação positiva entre piores condições socioeconômicas e maior exposição a risco ambiental.
} 
cas. Este fenômeno revela um aumento da desigualdade ambiental, no município de São Paulo, no período recente.

Os resultados também revelaram que a população residente em áreas de risco ambiental (próximas de cursos d'água e com altas declividades) apresenta condições socioeconômicas significativamente piores do que aquela residente fora destas áreas. Todos os indicadores considerados apontaram para a existência de piores condições socioeconômicas nas áreas de risco ambiental (próximas até 50 metros de cursos d'água e/ou com declividade acima de $30 \%$ ), seja para o total do município de São Paulo, seja para o conjunto de regiões pobres e periféricas. Entre estes indicadores, destacam-se diferenciais mais expressivos para o acesso à rede pública de esgotamento sanitário e para a porcentagem de população residente em setores subnormais (favelas). Portanto, os resultados das análises confirmaram a hipótese da existência de associação positiva entre maior exposição a risco ambiental e piores condições socioeconômicas.

\section{Referências bibliográficas}

ACSELRAD, H.; HERCULANO, S.; PÁDUA, J. A. (Orgs.). Justiça ambiental e cidadania. Rio de Janeiro: Ed. Relume-Dumará, 2004.

ALVES, H. P. F. Vulnerabilidade socioambiental na metrópole paulistana: uma análise sociodemográfica das situações de sobreposição espacial de problemas e riscos sociais e ambientais. Revista Brasileira de Estudos de População, São Paulo, v. 23, n. 1, p. 43-59, jan./jun. 2006.

BULLARD, $R$. Dumping in dixie: race, class, and environmental quality. San Francisco: Westview Press, 1990.

BUZZELLI, M.; JERRETT, M.; BURNETT, R.; FINKLESTEIN, N. Spatiotemporal perspectives on air pollution and environmental justice. In: ASSOCIATION OF AMERICAN GEOGRAPHERS. Annals... 93(3), 2003, p. 557-573.
Para além da confirmação dessa hipótese, a análise empreendida permitiu dimensionar o fenômeno da desigualdade ambiental em São Paulo, em termos quantitativos e espaciais, identificando os grupos sociais mais expostos ao risco ambiental, sua localização espacial e o número de pessoas envolvidas.

Nesse sentido, cabe destacar que a identificação e a caracterização de alguns padrões específicos de sobreposição espacial de situações de pobreza e risco ambiental, existentes no município de São Paulo, requerem o desenvolvimento de análises muito detalhadas, tais como aquelas possibilitadas pelos sistemas de informações geográficas, utilizando-se unidades espaciais de análise extremamente desagregadas, como os setores censitários e as áreas de ponderação dos censos demográficos. Portanto, uma possível contribuição deste trabalho é dar visibilidade às situações de desigualdade ambiental no município, podendo trazer subsídios relevantes para o planejamento de políticas públicas sociais e ambientais, tais como habitação e saneamento.

CUTTER, S. Race, class, and environmental justice. Progress in Human Geography, 19, p. 107-118, 1995.

HERCULANO, S. Riscos e desigualdade social: a temática da Justiça Ambiental e sua construção no Brasil. In: ENCONTRO DA ASSOCIAÇÃO NACIONAL DE PÓSGRADUAÇÃO E PESQUISA EM AMBIENTE E SOCIEDADE, 1, Indaiatuba, 2002. Anais... Campinas: Anppas, 2002.

HOGAN, D. J. População, pobreza e poluição em Cubatão. In: MARTINE, G. (Org.). População, meio ambiente e desenvolvimento: verdades e contradições. Campinas: Abep/Editora da Unicamp, 1993, p. 101-131.

HOLIFIELD, R. Defining environmental justice and environmental racism. Urban Geography, 22 (1), p. 78-90, 2001. 
JACOBI, P. R. Moradores e meio ambiente na cidade de São Paulo. Cadernos CEDEC, São Paulo, n. 43, 1995.

KRIEG, E. The two faces of toxic waste: trends in the spread of environmental hazards. Sociological Forum, 13, p. 3-20, 1998.

MARQUES, E. Espaço e grupos sociais na virada do século XXI. In: MARQUES, E.; TORRES, H. (Orgs.). São Paulo: segregação, pobreza e desigualdades sociais. São Paulo: Editora Senac, 2005, p. 57-80.

MARQUES, E.; TORRES, H. (Orgs.). São Paulo: segregação, pobreza e desigualdades sociais. São Paulo: Editora Senac, 2005, $329 \mathrm{p}$.

MOST, M.; SENGUPTA, R.; BURGENER, M. Spatial scale and population assignment choices in environmental justice analyses.

The Professional Geographer, 56(4), p. 574-586, 2004.

NAPTON, M. L.; DAY, F. A. Polluted neighborhoods in Texas: who lives there.

Environment and Behavior, 24, p. 508526, 1992.

PASTOR, M.; SADD, J; HIPP, J. Which came first? Toxic facilities, minority move-in, and environmental justice. Journal of Urban Affairs, 23, p. 1-21, 2001.

PULIDO, L. Rethinking environmental racism: white privilege and urban development in southern California. In: ASSOCIATION OF
AMERICAN GEOGRAPHERS, 90. Annals... 2000, p. $12-40$.

TASCHNER, S. P. Degradação ambiental em favelas de São Paulo. In: TORRES, H.; COSTA, H. (Orgs.). População e meio ambiente: debates e desafios. São Paulo: Editora Senac, 2000, p. 271-297.

TORRES, H. A fronteira paulistana. In: MARQUES, E.; TORRES, H. (Orgs.). São Paulo: segregação, pobreza e desigualdades sociais. São Paulo: Editora Senac, 2005, p. 101-119.

. A demografia do risco ambiental. In: TORRES, H.; COSTA, H. (Orgs.). População e meio ambiente: debates e desafios. São Paulo: Editora Senac, 2000, p. 53-73.

Desigualdade ambiental em

São Paulo. Tese (Doutorado em Ciências Sociais). Campinas: IFCH-Unicamp, 1997. $255 \mathrm{p}$.

TORRES, H.; MARQUES, E. Tamanho populacional das favelas paulistanas. Ou os grandes números e a falência do debate sobre a metrópole. In: ENCONTRO NACIONAL DE ESTUDOS POPULACIONAIS, 13, Ouro Preto, 2002. Anais... Belo Horizonte: Abep, 2002.

Reflexões sobre a hiperperiferia: novas e velhas faces da pobreza no entorno metropolitano. Revista Brasileira de Estudos Urbanos e Regionais, n. 4, p. 49-70, 2001.

\section{Resumen}

Desigualdad ambiental en el municipio de San Pablo: análisis de la exposición diferenciada de grupos sociales a situaciones de riesgo ambiental a través del uso de metodologías de geoprocesamiento

Este trabajo procura operacionalizar empíricamente el concepto de desigualdad ambiental, para identificar y caracterizar situaciones de desigualdad ambiental en el municipio de San Pablo, a través de la utilización de metodologías de geoprocesamiento. El objetivo es verificar y medir la existencia (o no) de asociación entre peores condiciones socioeconómicas y mayor exposición al riesgo ambiental. De esta forma, son analizados los diferentes grupos sociales expuestos a situaciones de riesgo ambiental, en el municipio de San Pablo. La hipótesis es que los riesgos ambientales son distribuidos de manera desigual entre los diferentes grupos sociales, así como el ingreso y el acceso a servicios públicos. Para comprobar esta hipótesis, se realizó un análisis comparativo de la dinámica demográfica y socioeconómica entre las 
poblaciones residentes en áreas de riesgo ambiental y aquéllas no residentes en estos tipos de área, con base en una tipología de la distribución espacial de los habitantes del municipio de San Pablo en tres grupos sociales (pobres, clase media y clase alta). Los resultados muestran que, en todos los grupos sociales, las poblaciones residentes en áreas de riesgo ambiental presentan condiciones socioeconómicas significativamente peores que las no residentes en esas áreas. Los resultados también revelan un aumento de la desigualdad ambiental, en el período reciente.

Palabras-clave: Desigualdad ambiental. Riesgo ambiental. Grupos sociales. Municipio de San Pablo. Poblaciones en situación de riesgo. Geoprocesamiento.

\section{Abstract}

Environmental inequality in the City of São Paulo, Brazil: analysis of differential exposure of social groups to situations of environmental risk by using geoprocessing methodologies

This article represents an effort at making operational the concept of environmental inequality, in order to identify and analyze situations of environmental inequality in the City of São Paulo, Brazil, by using geoprocessing methodologies. The objective is to identify and measure the association between unfavorable socioeconomic conditions and greater exposure to environmental risks, by analyzing the level of risk exposure of different social groups in São Paulo. The results show that, in all social groups, people living in risky areas have much lower socioeconomic conditions than those who living in other places. The results also show that environmental inequality in São Paulo has been increasing in recent years.

Keywords: Environmental inequality. Environmental risk. Social groups. São Paulo. Populations at risk. Geoprocessing. 